\title{
A new joining-device for manufacturing tubular butt joints with higher curing temperatures of film adhesives
}

\author{
Martin Johannes Schollerer ${ }^{*}$ (D), Jens Kosmann, Thomas Löbel, Dirk Holzhüter and Christian Hühne
}

*Correspondence:
martin.schollerer@dlr.de
DLR-Institute of Composite
Structures and Adaptive
Systems, Lilienthalplatz 7,
38108 Brunswick, Germany

*Correspondence: martin.schollerer@dr.de Structures and Adaptive 38108 Brunswick, Germany

\begin{abstract}
For detailed stress distribution analysis of bondlines, non-linear finite element analysis (FEA) is necessary. Depending on the load case in relation to shear and tension/ compression adhesives show a different behaviour of the yield point [1], which is e.g. included in the Mahnken and Schlimmer [2] model. State of the art for biaxial tested adhesive material-characteristics is the use of bonded tubular butt joints under variable torsion and tension loads. Important for the quality of the determined material values is the alignment of both tubes. The quality is significantly improved, if both tubes are aligned perfectly coaxial. Also, the bondline has to be free of voids. In previous work [3], Wölper investigated the effects of coaxial and angle deviations for the results of material characteristics using FEA. A slight deviation has a strong negative impact to the results. Particularly for thin film-adhesives with elevated curing temperatures, the change of viscosity of the adhesive and the thermal expansion of the tubes must be considered. Previous investigations regarding the manufacturing of the specimens showed shortfalls in joining and curing them. Due to voids, geometric deviations or poorly-bonded tubes, no reliable results were achieved yet. Therefore, a new assemblydevice is developed and tested. The results show well joined tubes without a signifcant angle deviation and with an average of $40 \mu \mathrm{m}$ in coaxial deviation. The thickness of the bondline can be adjusted and is constant over the whole diameter. The new joining-device enables the testing of tubular butt joints to determine biaxial material values of thin higher-temperature-cured film-adhesives. The device is patented to DE 102017114538.9.
\end{abstract}

Keywords: Adhesive bonding, Tubular butt joint, Joining device, Elevated curing temperature, Biaxial testing

\section{Background}

In order to use the potentials of carbon-fibre-reinforced-polymer (CFRP) as a light weight structure material, not only CFRP material characteristics are important. Further, adhesive bonding, with its good characteristics [4] for joining fibre reinforced plastics, leads to weight reduction. A major point of interest is the acquisition of precise material characteristics of adhesives. In order to design adhesive joints with finite element analysis (FEA) simulations, high sophisticated material models as Mahnken and Schlimmer, Drucker Prager or TAPO should be used in a continuum mechanic simulation approach. All of the models need biaxial material data. One possible solution is

(c) The Author(s) 2017. This article is distributed under the terms of the Creative Commons Attribution 4.0 International License (http://creativecommons.org/licenses/by/4.0/), which permits unrestricted use, distribution, and reproduction in any medium, provided you give appropriate credit to the original author(s) and the source, provide a link to the Creative Commons license, and indicate if changes were made. 
the use of arcan specimen [5]. According to the literature, arcan specimens can be used, but bonded specimens require complex test assemblies and are costly in manufacturing. Tubular butt joints allow for combined tension-torsion tests overcoming the need to use different sample types for different loading conditions.

For adhesives, curing at room temperature, the adhesive has to be inserted into the bonding area. It must be sealed to prevent a squeeze out. Applied pressure prevents air inclusion and avoids void formation within the bondline. Typically the tubes are aligned in a prism and simply clamped as shown in Fig. 1. Figure 2 shows the aligned tubes which are clamped a second time with small prisms near the bondline to fix the tubes for curing. Film adhesives with elevated curing temperatures like Hysol ${ }^{\circledR}$ EA9695 [6] typically cure above $120{ }^{\circ} \mathrm{C}$. This causes a problem through thermal expansion during the cure process. Not only the adherends expand, but also the clamping device. Depending on the clamping force and friction the alignment of the tubes is either lost or an overpressing of the bondline is a consequence.

If the setup, as described above, is used the pressure to the bondline by clamping is lost as soon as the adhesive becomes liquid. Voids and air inclusion result as seen in

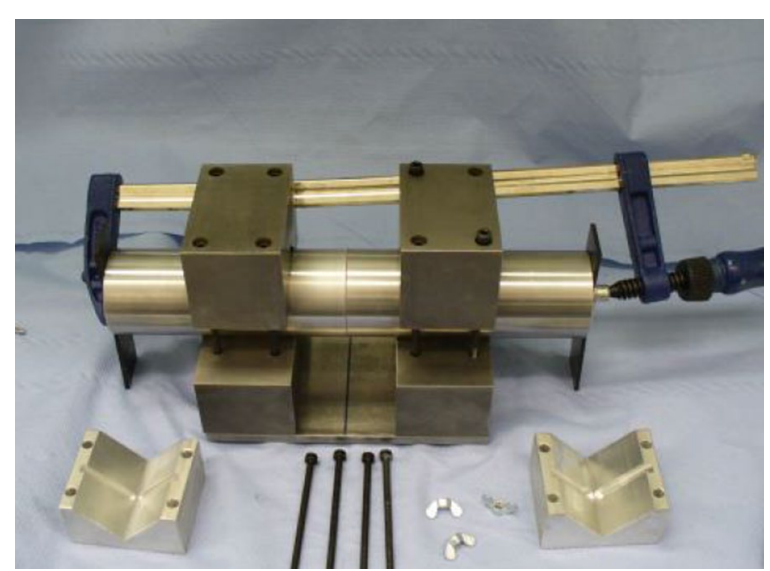

Fig. 1 Alignment and bondline pressing

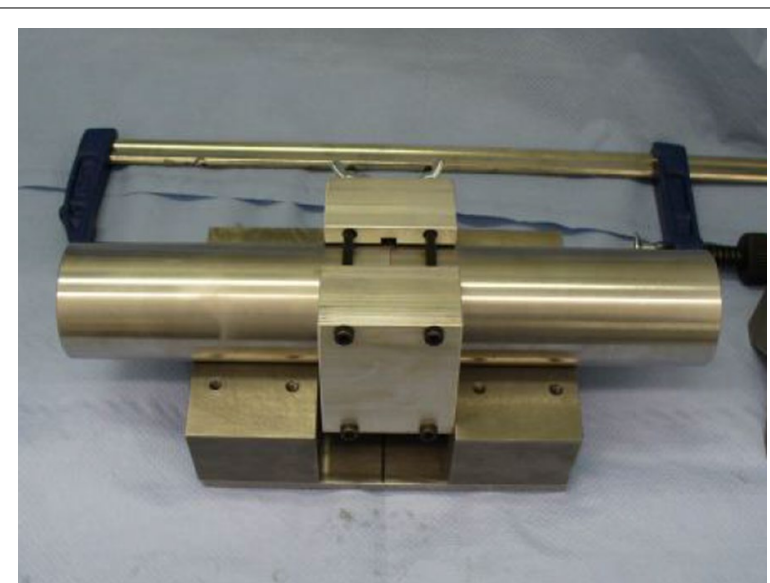

Fig. 2 Clamping for cure with prism 
Fig. 3. The thinning effect of film adhesives increases this effect additional due to the limited amount of material within the bond.

Based on experiences from first trials another approach is taken to align both tubes during cure. By clamping only one tube and guiding the other, consolidation force is applied by an additional weight on the guided adherend to provide the sufficient pressure to the adhesive. The result is an improved quality of the bondline but results in an unintentional variation of $25 \%$ in bondline thickness. Material tests of five specimens revealed a shear-strengths variation of $20 \%$ and a variation of ultimate shear strain of $27 \%$.

In a study, Wölper [3] described the effects of geometrical deviations to the stress distribution within the bondline of hollow tubular butt joints by using non-linear elastoplastic FEA simulation. According to test regulations, [7] the coaxial deviation of an outer tube with a diameter of $60 \mathrm{~mm}$ has to be smaller than $0.06 \mathrm{~mm}$. Wölper identified strength critical stress peaks at the free edge of bondline beginning with deviations of $0.05 \mathrm{~mm}$ under torsion loading.

Derived from Wölper, requirements for tubular butt joints are the following:

- Homogeneous bondline thickness

- Coaxial deviation smaller than $0.05 \mathrm{~mm}$

- Angle deviation smaller than $0.031^{\circ}$

- No air inclusion or voids in the bondline

The aim of the presented joining concept is to increase the specimen quality whereby the variance of test results should decrease. A new concept for joining the tubes is developed and presented.

\section{Materials and experimental methods}

\section{Working principle}

Figure 4 shows the concept of the joining device. The idea for the concept is the usage of different thermal expansions. An inner core, with a higher thermal expansion coefficient

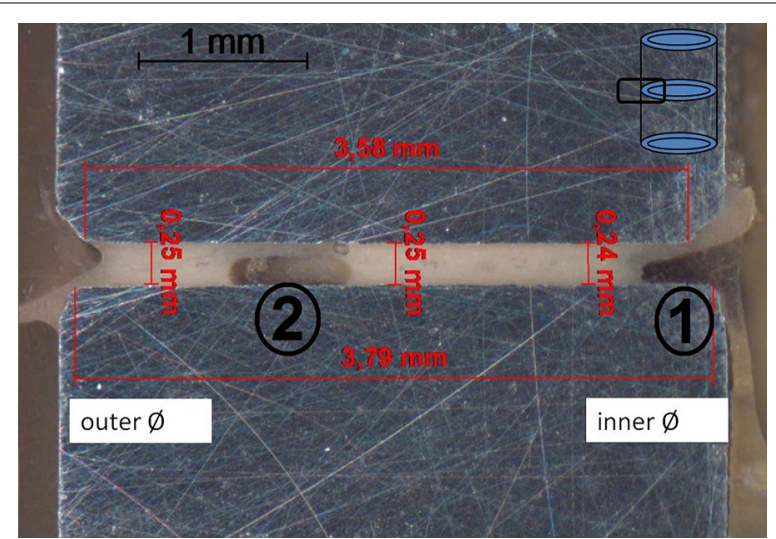

Fig. 3 Example of a void (1) and an air inclusion (2). Consequence of clamping the adherends during the adhesive cure 


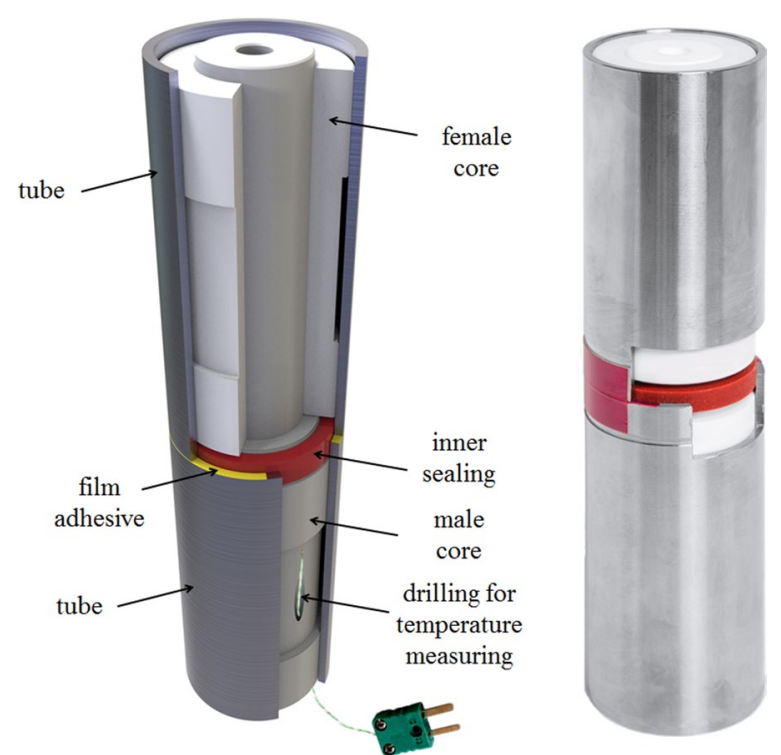

Fig. 4 Concept and demonstrator of the new joining device

(CTE) than the tube material, expands during the cure-process of the adhesive. The core aligns the tubes as the curing temperature is hit.

To prevent a gap between both tubes due to an axially thermal expansion, the core has to be divided into two parts. A male and a female part of the core result which have a small loose fit to each other, minimising the coaxial tolerances. Being the same material with the same thermal expansion, the bearing persists over the entire temperature range of the cure cycle. The core has a sealing element to prevent an excessive adhesive flow from the bondline to the core. An outer sealing of the bondline is realised by a heat resistant tape. With a weight on top of the tubes, a consolidation force is applied to the bondline to prevent any voids and air inclusions.

\section{Calculation of design parameters}

The calculation of core and sealing diameters uses the simplified analytical equation for thermal expansion of solid materials

$$
\Delta \mathrm{l}=\mathrm{l}_{0} \cdot \alpha \cdot \Delta \mathrm{T}
$$

In Eq. $1, \Delta \mathrm{l}$ is the change in length due to the thermal expansion, $\mathrm{l}_{0}$ is the original length, $\alpha$ the thermal expansion coefficient (CTE) and $\Delta \mathrm{T}$ the change of temperature. To calculate the different diameters of the sealing element and the core, Eq. 1 has to be transformed and inserted by following variables (Table 1).

The equation is transformed to:

$$
D_{C}=\frac{D_{T, i} \cdot\left(1+\alpha_{T}+\left(T_{\text {cur }, s} \cdot T_{\text {env }}\right)\right)}{1+\alpha_{C}+\left(T_{\text {cur }, s} \cdot T_{\text {env }}\right)}
$$

The diameter $\mathrm{D}_{\mathrm{c}}$ of the core at environmental temperature can be calculated by Eq. 2 . The sealing diameter can be calculated by changing the thermal expansion coefficient $\alpha_{C}$ 
Table 1 Labels of variables used in Eq. (2)

\begin{tabular}{ll}
\hline Variable & Label \\
\hline$D_{C}$ & Diameter of core \\
$D_{T, i}$ & Inner diameter of tube \\
$a_{C}$ & Thermal expansion coefficient of core material \\
$a_{T}$ & Thermal expansion coefficient of tube material \\
$T_{\text {cur, }}$ & Start cure temperature of adhesive \\
$T_{\text {env }}$ & Environmental temperature \\
\hline
\end{tabular}

Table 2 Material selection with thermal expansion coefficient (from [9-11],) the onset temperature and diameter in the joining device

\begin{tabular}{llll}
\hline Material & $\begin{array}{l}\text { Thermal coefficient of expansion } \\
(\mathbf{1} / \mathbf{K})\end{array}$ & Temperature of onset $\left({ }^{\circ} \mathbf{C}\right)$ & Diameter at $\mathbf{2 3}{ }^{\circ} \mathbf{C}(\mathbf{m m})$ \\
\hline Stainless steel & $16 \cdot 10^{-6}$ & - & 54 \\
PTFE & $130 \cdot 10^{-6}$ & 120 & 53.41 \\
Silicone & $260 \cdot 10^{-6}$ & 90 & 53.13 \\
\hline
\end{tabular}

to the sealing value $\alpha_{S}$. The higher temperature $T_{\text {cur,s }}$ is set to the temperature $T_{v}$ where the viscosity of the adhesive falls below $1000 \mathrm{~Pa}$ s. A squeeze out of adhesive needs to be prevented.

\section{Selection of materials}

Based on the testing requirements [7] stainless steel is chosen as the material for the tubes to enable testing under environmental conditions. Polytetrafluoroethylene (PTFE) is chosen as core material due to its chemical resistance and its release property to epoxy adhesives [8]. PTFE has a thermal stability up to $260{ }^{\circ} \mathrm{C}$ [9] and exhibits additionally good sliding properties. With its reduced material-stiffness, silicone is good for the sealing and is selected therefor (Table 2).

$\mathrm{Hysol}^{\circledR}$ EA9695 is used as film adhesive for the bonding. Differential scanning calorimetry (DSC) analysis identifies the onset of cure at $120^{\circ} \mathrm{C}$ and the highest curing rate at $130{ }^{\circ} \mathrm{C}$. Measurements reveal the point of lowest viscosity of $1000 \mathrm{~Pa}$ s is at $90{ }^{\circ} \mathrm{C}$ [12] for EA 9695.

\section{Results and discussion}

The first test without adhesive is done to prove the function of coaxial alignment without manifesting a gap between the tubes as seen in Fig. 5 . The assembly is heated up to $130{ }^{\circ} \mathrm{C}$ in a regular oven. Both tubes fit without a gap and are orientated well. Both cores expand to the tube walls and form a tight fit. By slightly pulling the upper and the lower part from each other at $130^{\circ} \mathrm{C}$ the upper part (core and tube) can be removed and joined easily.

The loose fit between the cores is conserved at curing temperature and is shown in Fig. 6.

\section{Temperature measurement}

Figure 4 shows an opening for insertion of a temperature sensor. Due to this, the temperature at the inner diameter of the tube is measured. Also, the temperature on the 


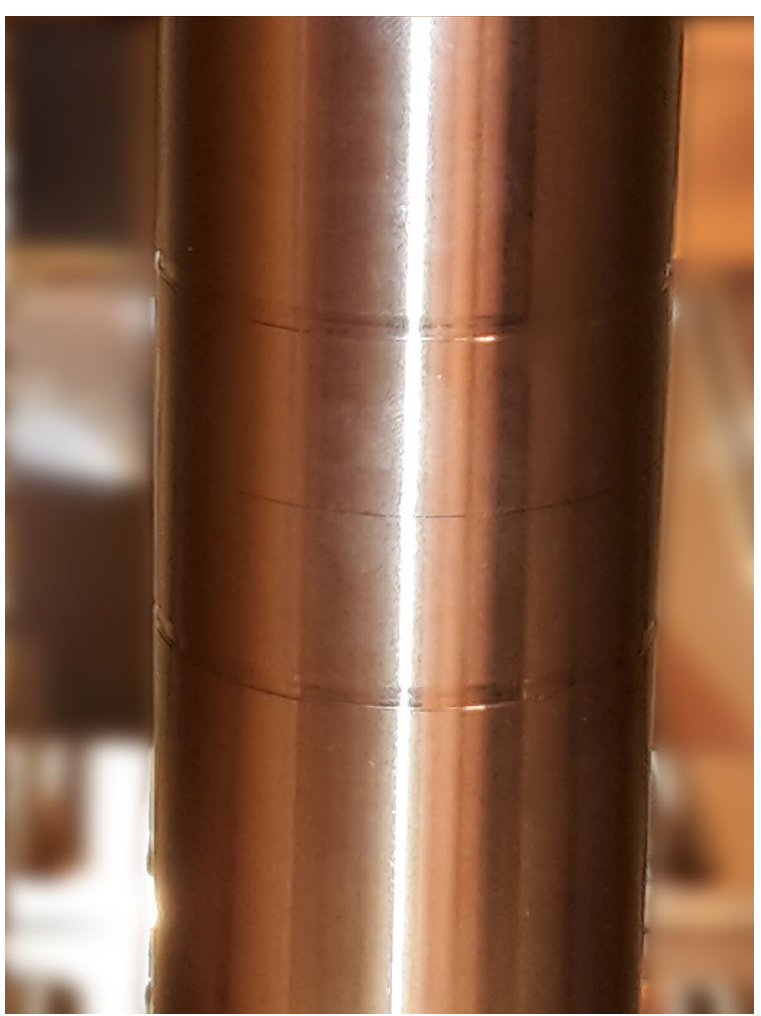

Fig. 5 Coaxial orientation and exclusion of gap between the tubes

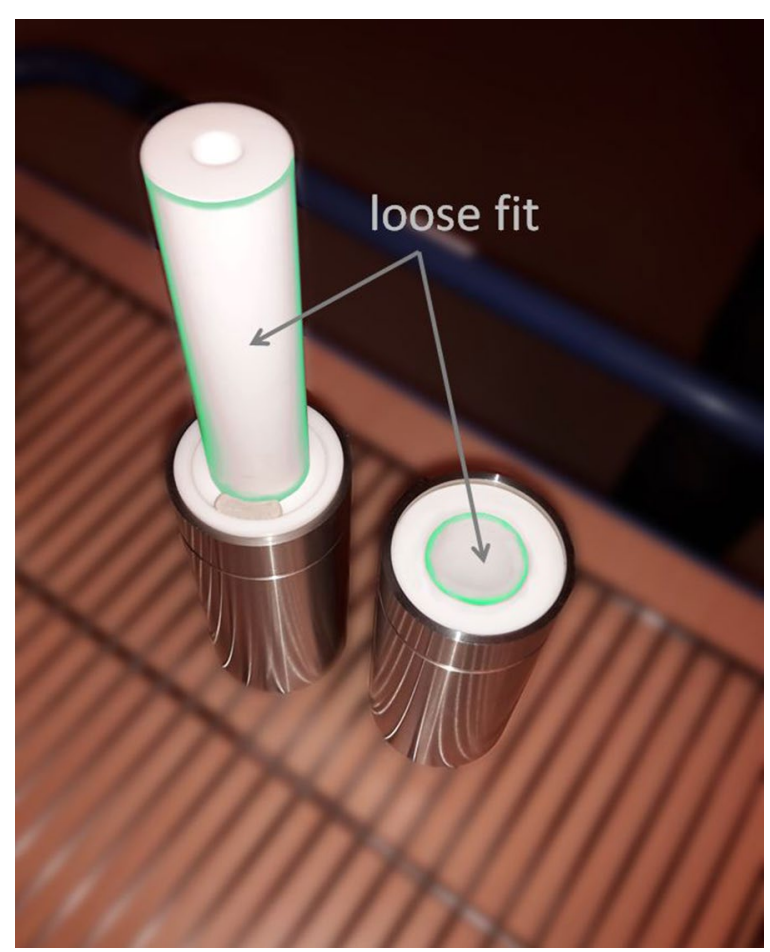

Fig. 6 Core-tube-unit at $130^{\circ} \mathrm{C}$ with loose fit 


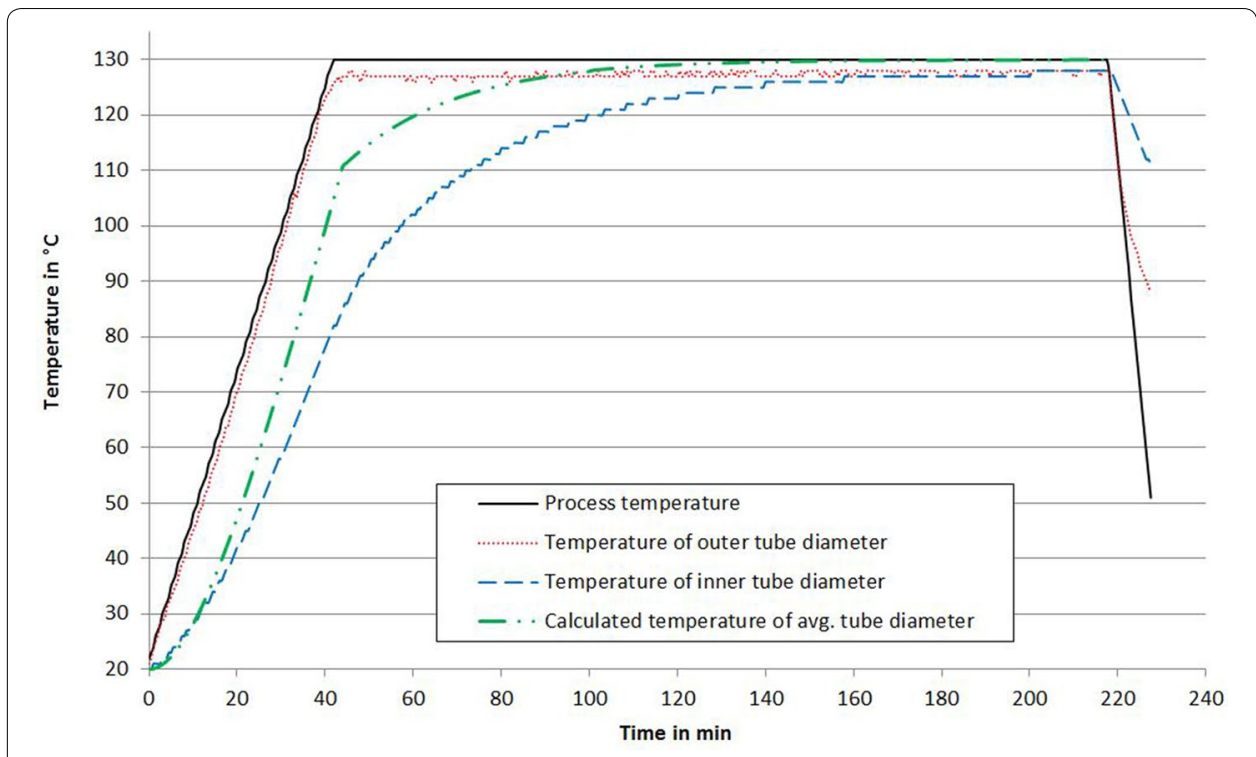

Fig. 7 Temperature measurements over the curing process for EA9695 film adhesive

outer side of the tubes is measured to ensure a homogeneous temperature profile over the tube and therefor, the bondline itself. Additionally, the necessary curing time at minimum $120^{\circ} \mathrm{C}$ is ensured. The diagram in Fig. 7 shows both measured temperatures on the inner and the outer diameter near the bondline, the analytical calculated temperature curve to heat up the tubes and the process temperature of the oven. The heat rate is $2.5 \mathrm{~K} / \mathrm{min}$.

The calculated curve shows the temperature of the middle diameter of the tubes.

\section{Surface preparation and alignment of tubes}

First, the bonding surfaces of the tubes are cleaned by acetone and isopropanol, then pre-treated by abrasive blasting with corundum F220 (0.05-0.07 mm, 2 bar) as described in [13]. After blasting, the tips are cleaned a second time in acetone and isopropanol bath and ventilated in an oven at $23{ }^{\circ} \mathrm{C}$ for $20 \mathrm{~min}$.

With the use of GOM ARAMIS 12M, an optical digital image correlation system (DIC), the geometry of the bonded tubular butt joint is scanned. A cylinder is fit to the surface of the geometry, so the coaxial deviations can be measured as shown in Fig. 8.

The angular deviations of the tubes centrelines are measured, too. The results for 20 specimens are shown in Table 3.

\section{Bondline inspection}

To ensure the quality of the bondline in homogeneous thickness, exclusion of voids or air, the specimen are cut and polished for microscopy. An average bondline thickness is measured to $40 \mu \mathrm{m}$ all over the bondline at three bar pressure during manufacturing.

The inner diameter of the bondline has a sharp sealing edge while the outer diameter side shows an increase of adhesive release. No voids and air inclusion can be identified. Figure 9 shows that the outer sealing tape does not hold the pressure of the adhesive during the cure-process and builds a curved adhesive spew. After removing the PTFE cores, no adhesive adhered to the silicone sealing or to the tape. 


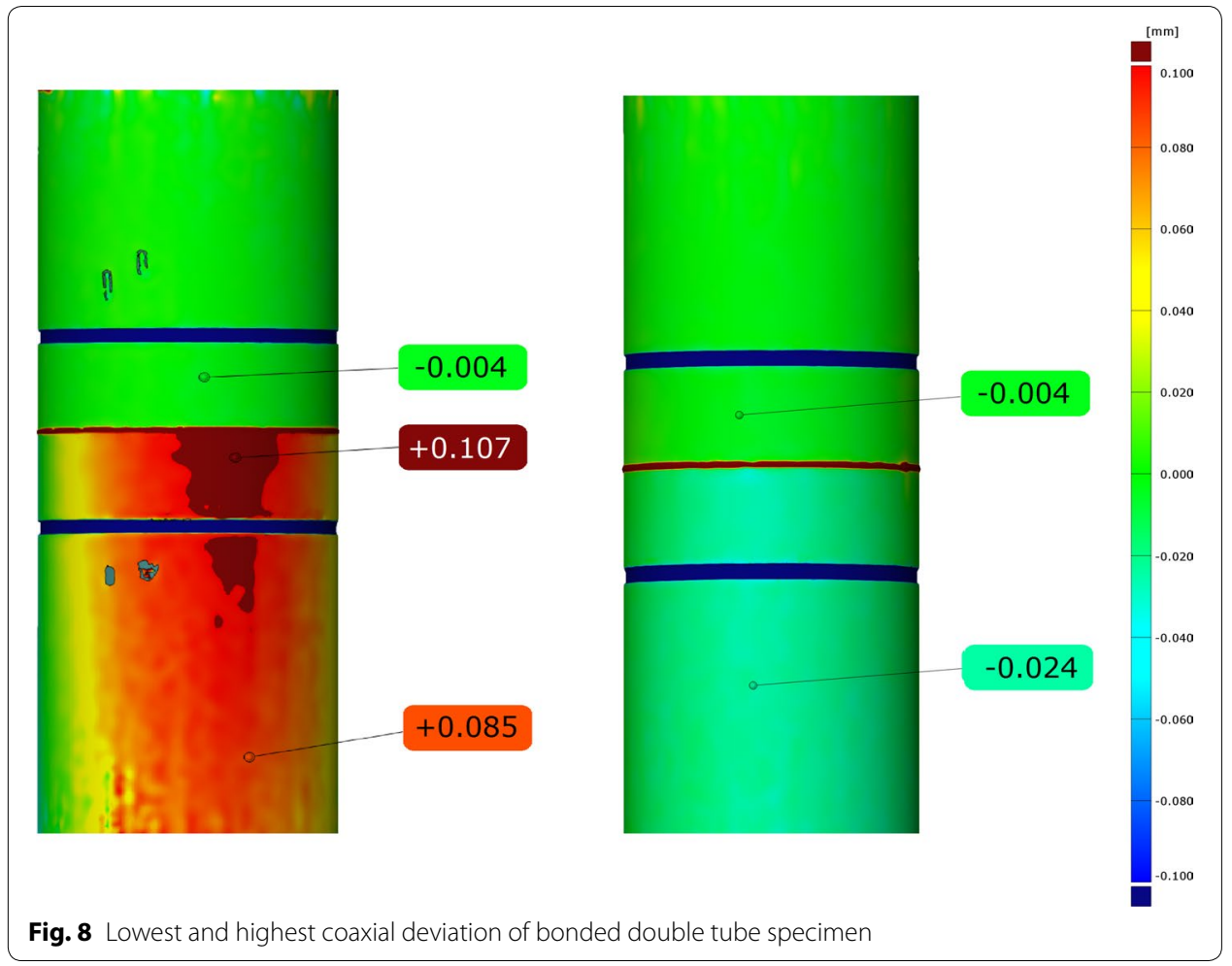

Table 3 Measured coaxial and angle deviations of 20 bonded specimen

\begin{tabular}{llllll}
\hline Deviation & Unit & Average & s & Min & Max \\
\hline Coaxial deviation & $\mathrm{mm}$ & 0.041 & 0.020 & 0.020 & 0.107 \\
Angle deviation & $\circ$ & 0.027 & 0.022 & 0.008 & 0.052 \\
\hline
\end{tabular}

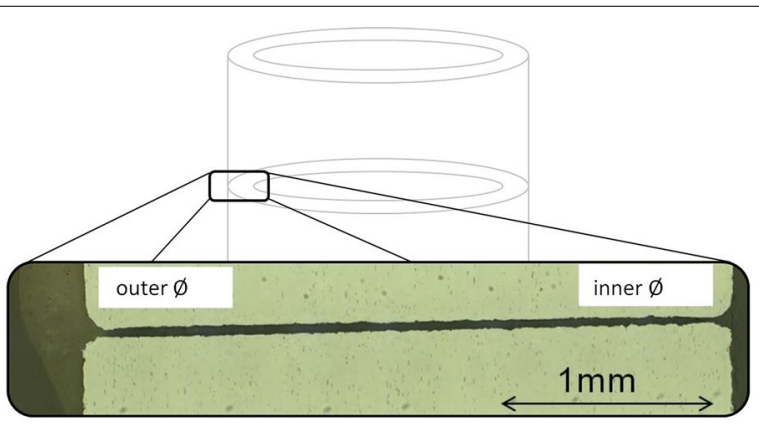

Fig. 9 Cured adhesive bondline, left side sealed by tape, right side sealed by silicone sealing

\section{Present test results}

As the project is still in progress, only 20 of 200 specimens are tested at the moment. Available results show a variation of $5.35 \%$ in maximum shear strength. In comparison to the literature [14], the absolute tested shear strength is $18 \%$ higher.

Manufacturing trials show an excellent joining device for hollow tubular butt joints with reproducible properties. The concept with the smaller diameters of the core and 
sealing enable an easy to use joining of the components. The parameters which influence the specimen's quality, only depend on the manufacturing quality of the male and female core. All manufactured specimen are free of voids and air inclusion and show the same bondline thickness. With $0.04 \mathrm{~mm}$ the bondline is at its minimum thickness guaranteed by an integrated polyvinyle carrier fleece. Typically wide bonded plates bonded with the adhesive show a thickness of $0.1 \mathrm{~mm}$. With the small wall thickness of $3 \mathrm{~mm}$ of the tubes, the adhesive leaks out till the carrying-fleece of the film adhesive is fully compressed. A possible solution is the stacking of additional adhesive layers. If the bondline thickness does not depend on the carrying fleece, another outer sealing concept needs to be used.

The coaxial and angular deviations are statistical smaller than the test regulations. To guarantee a proper basis for FEA input data [3] more tests need to be done.

From the present test results, the variation of material values decreased by a factor 4. But there is no information about the maximum strain of the specimens in test. All variables with negative impact to the test results are mitigated. The new concept allows testing of film adhesives with elevated curing temperatures in tubular butt joints and ensures high quality material data.

\section{Conclusion}

A new concept for manufacturing tubular butt joint specimens for biaxial film adhesive material characteristics is presented. While the different thermal expansions are the main problem for manufacturing tubular butt joints with film adhesives in the past, the presented new joining concept utilizes these to align both adherends during the curing. The quality of bondline and the accuracy of orientation of the tubes are strongly increased. At this time the material tests show a decrease of variation in results of factor 4. The joining device is registered to Patent Number DE 102017114538.9.

Further investigations have to ensure the adjustment of the bondline thickness by varying the number of adhesive film layers. Otherwise the concept must to be redesigned to comply with this requirement. Hollow tubular butt joints are now cheap to manufacture and provide a high quality and a low variation of test data for different loading states in one type of specimen.

Authors' contributions

MJS, JKo, DHo and CHu are the developer of the named patent. TLo supported with surface pre-treatment before bonding. All authors read and approved the final manuscript.

\section{Acknowledgements}

The authors thank the German Ministry of Commerce for the funding of the FACTOR project. DLR thanks the FhG. IFAM for testing the specimen.

\section{Competing interests}

The authors declare that they have no competing interests.

Availability of data and materials

Not applicable.

Consent for publication

Not applicable.

Ethics approval and consent to participate

Not applicable.

Funding

Not applicable. 


\section{Publisher's Note}

Springer Nature remains neutral with regard to jurisdictional claims in published maps and institutional affiliations.

Received: 17 August 2017 Accepted: 18 September 2017

Published online: 20 September 2017

\section{References}

1. Bornemann J, Schlimmer M. Berechnungen und Auslegung von Klebverbindungen (Teil 2). Adhaes Kleb Dicht. 2004;48:40-2. doi:10.1007/BF03251309.

2. Mahnken R, Schlimmer M. Simulation of strength difference in elasto-plasticity for adhesive materials. Int J Numer Methods Eng. 2005;63:1461-77. doi:10.1002/nme.1315.

3. Wölper J, Löbel T, Kosmann J. Usability of tube torsion/tension test for determination of film adhesive material properties. Conference report. AB2015 Porto, Portugal, 2-3 July 2015. 2015.

4. Habenicht G. Kleben-erfolgreich und fehlerfrei, vol. 6. Berlin: Vieweg + Teubner; 2012. p. 2-3. doi:10.1007/978-3-8348-8316-2.

5. Cognard J, Cèac'hcadec R, Sohier L, Davies P. Analysis of the nonlinear behavior of adhesives in bonded assemblies_Comparison of TAST and Arcan tests. Int J Adhes Adhes. 2008:28:393-404. doi:10.1016/j.ijadhadh.2008.04.006.

6. Henkel, Hysol EA 9695. Epoxy film adhesive technical report. Henkel Corporation, Rev.1/01. 2017.

7. DIN EN 14869-1. Structural adhesives-determination of shear behaviour of structural bonds_-Part 1: Torsion test method using butt-bonded hollow cylinders German version. Germany. 2011.

8. Badey J, Espuche E, Jugnet Y, Chabert B, Duc Tran Minh. Influence of chemical and plasma treatments on the adhesive properties of PTFE with an epoxy resin. Int J Adhes Adhes. 1996;16:173-8. doi:10.1016/0143-7496(95)00042-9.

9. KELUX Kunststoffe GmbH. Eigenschaften PTFE-material datasheet, Germany. 2016.

10. DEW-Stahl. Werkstoffdatenblatt 1.4305-material datasheet, Germany. 2017.

11. Silicone I. Technische Daten und Verarbeitungshinweise-material datasheed, Germany. 2016.

12. Löbel T. The Hybrid bondline: a novel disbond-stopping design for adhesively bonded composite joints. Dissertation, Technische Universität Braunschweig, Germany. 2016.

13. ISO 17212. Structural adhesives-guidelines for the surface preparation of metals and plastics prior to adhesives bonding, Switzerland. 2012.

14. Tomblin J et al. Shear stress-strain data for structural adhesives, Federal Aviation Administration, USA DOT/FAA/ AR-02/97. 2002.

\section{Submit your manuscript to a SpringerOpen ${ }^{\odot}$ journal and benefit from:}

- Convenient online submission

- Rigorous peer review

- Open access: articles freely available online

- High visibility within the field

- Retaining the copyright to your article

Submit your next manuscript at $\gg$ springeropen.com 